\title{
Mechanistic Explanation of the pH Dependence and Onset Potentials for Hydrocarbon Products from Electrochemical Reduction of $\mathrm{CO}$ on $\mathrm{Cu}(111)$
}

\author{
Hai Xiao, Tao Cheng, William A. Goddard III,* and Ravishankar Sundararaman \\ Materials and Process Simulation Center (MSC) and Joint Center for Artificial Photosynthesis (JCAP), California Institute of \\ Technology, Pasadena, California 91125, United States
}

\section{Supporting Information}

ABSTRACT: Energy and environmental concerns demand development of more efficient and selective electrodes for electrochemical reduction of $\mathrm{CO}_{2}$ to form fuels and chemicals. Since $\mathrm{Cu}$ is the only pure metal exhibiting reduction to form hydrocarbon chemicals, we focus here on the $\mathrm{Cu}$ (111) electrode. We present a methodology for density functional theory calculations to obtain accurate onset electrochemical potentials with explicit constant electrochemical potential and $\mathrm{pH}$ effects using implicit solvation. We predict the atomistic mechanisms underlying electrochemical reduction of $\mathrm{CO}$, finding that (1) at acidic $\mathrm{pH}$, the $\mathrm{C}_{1}$ pathway proceeds through $\mathrm{COH}$ to $\mathrm{CHOH}$ to form $\mathrm{CH}_{4}$ while $\mathrm{C}_{2}\left(\mathrm{C}_{3}\right)$ pathways are kinetically blocked; $(2)$ at neutral $\mathrm{pH}$, the $\mathrm{C}_{1}$ and $\mathrm{C}_{2} \quad\left(\mathrm{C}_{3}\right)$ pathways share the $\mathrm{COH}$ common intermediate, where the branch to $\mathrm{C}-\mathrm{C}$ coupling is realized by a novel $\mathrm{CO}-\mathrm{COH}$ pathway; and (3) at high $\mathrm{pH}$, early $\mathrm{C}-\mathrm{C}$ coupling through adsorbed $\mathrm{CO}$ dimerization dominates, suppressing the $\mathrm{C}_{1}$ pathways by kinetics, thereby boosting selectivity for multi-carbon products.

$\mathrm{E}$ lectrochemical reduction of $\mathrm{CO}_{2}(\mathrm{CO} 2 \mathrm{RR})$ to fuel and chemical products using renewable electricity is a promising technique to achieve carbon neutrality under mild conditions. Copper is the only known electrode material that delivers appreciable amounts of hydrocarbons, primarily methane and ethylene, with minor alcohol products. ${ }^{1-6}$ However, $\mathrm{Cu}$ exhibits high overpotentials and a lack of selectivity that precludes economic applications. For practical electrochemical reduction of $\mathrm{CO}_{2}$ to fuels and chemicals, it is essential to find a new more efficient and more selective electrode.

To provide guidelines for such rational design, we apply quantum mechanics (QM) methods to develop a mechanistic understanding of the processes on $\mathrm{Cu}$. We want to emphasize at the beginning that there are many uncertainties on how to use QM to obtain reliable predictions about electrocatalysis. To be useful in guiding design and comparing to experiment, it is essential that the reaction barriers be accurate to $\sim 0.1 \mathrm{eV}$ and that the predicted onset potentials be accurate to $\sim 0.1 \mathrm{~V}$. To be practical, we need to use density function theory (DFT), but major questions arise as to which "flavor" to use: LDA, PBE, B3LYP, M06, etc. Moreover, to be practical, the number of atoms per unit cell must be limited to $\sim 200$ atoms, which creates severe limitations on how the solvent is treated. Do we use a continuum solvent description, and which one, or do we try to include part of the solvent explicitly? The experiments are done under conditions in which the applied potiential is fixed, whereas calculations are far easier to apply to the condition of constant number of electrons. How do we use the QM to relate to the experimental conditions? The experiments are referenced to the standard hydrogen electrode (SHE) at which the free energy of a proton at $\mathrm{pH}=0$ is in equilibrium with $\mathrm{H}_{2}$ gas at standard conditions, whereas the theory most conveniently deals with the Fermi energy with respect to the vacuum. How should we handle this? The relevant quantities in rates are free energies at the reaction temperature, whereas the QM most easily deals with the energies or enthalpies. For each of these issues, it is difficult to validate against experiment because discrepancies might involve various combinations of all the approximations. Instead our strategy is to tackle all the above issues simultaneously with methods that we consider likely to be both valid and practical, and we test all the approximations simultaneously by predicting how the results depend on experimental variables such as $\mathrm{pH}$ and applied potiential for a system where the experiments have been done very carefully and where it is known that the product ratios and rates depend sensitively on the $\mathrm{pH}$ and potential. Indeed, for CO2RR on $\mathrm{Cu}$ (111), we find excellent agreement with experiment for the onset potentials of producing various hydrocarbon products over the range of $\mathrm{pH}$ from 1 to 13 .

We claim that this excellent agreement with experiment for the calculations reported here validates that the particular combination of choices we have made is sufficiently accurate for the particular problem we have chosen to address, providing a sound basis on which to tackle other electrochemical catalysis problems. This provides a starting point for studies of other electrochemical systems, such as CO2RR on other surfaces of $\mathrm{Cu}$, on alloys of $\mathrm{Cu}$, and on other metals, metal oxides, metal nitrides, etc. Moreover, it provides a starting point to consider other electrochemical processes such as ORR, OER, etc. Our plan is to procced cautiously with other sytems using the same combinations of methods to predict the properties of new electrocatalysts for systems that can be studied experimentally. We expect that this will lead gradually to developing a validated QM-based technology for making reliable predictions on

Received: October 30, 2015

Published: December 30, 2015 
electrocatalysis in advance of experiment. This paper is meant to provide the first step toward this goal. In addition, it provides a detailed reaction mechanism explaining the very complex ways that the products of CO2RR on $\mathrm{Cu}$ (111) depend on applied potential and $\mathrm{pH}$, which we expect to be useful in designing modified catalysts or conditions.

In $\mathrm{CO}_{2}$ reduction on $\mathrm{Cu}, \mathrm{CO}$ is produced at the lowest overpotential and the electrochemical reduction of $\mathrm{CO}$ gives the same product spectrum as that of $\mathrm{CO}_{2}{ }^{7,8}$ Thus, it is believed that $\mathrm{CO}$ is the essential intermediate linking $\mathrm{CO}_{2}$ to more reduced products, and we focus here electrochemical reduction of CO.

Several QM computational investigations have suggested rationalizations of experimental results ${ }^{3-5,8-10}$ in terms of postulated mechanisms for $\mathrm{CO}$ electrochemical reduction (COER) on $\mathrm{Cu}$ surfaces. In 2010, Peterson et al. ${ }^{11}$ examined this reaction for the $\mathrm{Cu}(211)$ surface and suggested a pathway along which the potential-limiting step is formation of $\mathrm{CHO}_{\mathrm{ad}}$ from protonation of $\mathrm{CO}_{\mathrm{ad}}$, concluding that $\mathrm{CHO}_{\mathrm{ad}}$ leads to both $\mathrm{CH}_{4}$ and $\mathrm{C}_{2} \mathrm{H}_{4}$. These calculations did not calculate reaction barriers and ignored solvation. Similar studies were reported by Calle-Vallejo et al., ${ }^{12}$ who proposed instead that $\mathrm{C}_{2}$ products arise from $\mathrm{C}-\mathrm{C}$ coupling between two $\mathrm{CO}_{\mathrm{ad}}$. These studies ignored reaction barriers and solvation and did not predict overpotentials and selectivity.

In 2013, Nie et al. ${ }^{13}$ reported transition states (TSs) for COER on $\mathrm{Cu}$ (111) but without full solvation. They concluded that the $\mathrm{COH}_{\mathrm{ad}}$ is the kinetically dominant key intermediate, leading to $\mathrm{CH}_{x}(x=0-4)$ species sequentially. $\mathrm{C}_{2} \mathrm{H}_{4}$ was proposed to form at the $\mathrm{CH}_{2}$ step, although this contradicts the experimental conclusion that pathways to $\mathrm{CH}_{4}$ and $\mathrm{C}_{2} \mathrm{H}_{4}$ branch at an early stage of COER, ${ }^{9,14}$ Indeed, Montoya et al. ${ }^{15}$ calculated the barriers of $\mathrm{CO}$ dimerization on $\mathrm{Cu}$ (111) and (100) and found them to be sufficiently low for C-C coupling to proceed early. This study used only a simple charged water layer to mimic the electrochemical environment for highly negative applied potentials.

In addition to ignoring full effects of solvent, all previous theoretical studies assumed constant numbers of electrons $\left(N_{\mathrm{e}}\right)$, whereas experimental electrochemical half-cells are open systems operating at constant electrochemical potentials $\left(\mu_{\mathrm{e}}\right)$. The calculations with constant $N_{\mathrm{e}}$ suffer from large variations in $\mu_{\mathrm{e}}$, leading to increases of $\sim 1 \mathrm{~V}$ in modeling $\mathrm{CO}$ dimerization. ${ }^{15}$ (The $\mu_{\mathrm{e}} N_{\mathrm{e}}$ contribution to free energies introduces significant deviations in the calculated reaction energy landscapes from the true values of constant $\mu_{\mathrm{e}}$ systems.) Such inconsistencies preclude quantitative estimates of onset potentials.

Moreover, previous studies examined only $\mathrm{C}_{1}$ or $\mathrm{C}_{2}$ pathways, whereas the major selectivity issue in COER is the competition between $\mathrm{C}_{1}$ and $\mathrm{C}_{2}$ pathways. Here $\mathrm{pH}$ is an ineluctable factor to consider, as shown by recent experiments. ${ }^{16}$ Indeed, we show here that this selectivity is strongly influenced by $\mathrm{pH}$, making it essential to include $\mathrm{pH}$ effect in determining selectivity.

First we establish a DFT methodology to predict onset potentials, which we combine with $\mathrm{pH}$ effects and implicit solvation to explicitly calculate the reactions at constant $\mu_{\mathrm{e}}$. This allows us to elucidate the competition among possible pathways of COER on $\mathrm{Cu}$ at various $\mathrm{pH}$, by calculating the free energy profiles while including both potential and $\mathrm{pH}$ dependence. Thus, we predict the onset potentials for $\mathrm{CH}_{4}$ and $\mathrm{C}_{2} \mathrm{H}_{4}$ as a function of $\mathrm{pH}$, leading to excellent agreement with experiment. We also find a $\mathrm{C}_{3}$ pathway, observed experimentally to account for a few percent products. Thus, we consider that the results in this paper validate the particular combinations of methods we have chosen. In addition, the mechanism established in this study provides insights likely to be essential for designing new electrodes to achieve high selectivity with low overpotentials.

In modeling the electrochemical half-cell, we assume that this open system is at dynamic equilibrium with a constant applied potential $U$, while the proton source $\left(\mathrm{H}_{3} \mathrm{O}^{+}\right.$or $\left.\mathrm{H}_{2} \mathrm{O}\right)$ and electron source are refilled instantly prior to every electrochemical reaction step. Thus, we can approximate the half-cell with a closed system in which the reaction energy profile is obtained using standard DFT techniques [see Supporting Information (SI) for details]. For a protonation step, our model uses a hydrogen atom bonded to the surface to locate the TS and then references this back to the $\mathrm{H}^{+}\left(\mathrm{H}_{3} \mathrm{O}^{+} / \mathrm{H}_{2} \mathrm{O}\right)+e^{-}$pair through $\mathrm{H}_{2}$ (details in SI). Thus, our model restores the reference energy of the correct initial state for the reaction energy profile, allowing the $\mathrm{pH}$ dependence to be introduced naturally.

Furthermore, we perform explicit constant $\mu_{\mathrm{e}}$ calculations for all states along the reaction coordinate. This is done through variationally optimizing $N_{\mathrm{e}}$ to minimize the grand free energy at fixed $\mu_{\mathrm{e}}$, and the resulted net electronic charge is balanced by ionic screening in the electrolyte, ${ }^{17}$ which is treated here using the CANDLE implicit solvation model. ${ }^{18}$ Consequently this provides a realistic description of the electrochemical interface, ${ }^{19}$ which includes both the external potential and solvation effects (details in SI). The final free energy profiles include zero-point energy, enthalpy, and entropy contributions from vibrations of surface species. For example, the free energy barrier $\Delta G^{\ddagger}$ for $\mathrm{COH}$ formation is given by

$$
\Delta G^{\ddagger}(\mathrm{COH})=0.63+0.0592 \times \mathrm{pH}-0.0959 \times U(\mathrm{eV})
$$

while $\Delta G^{\ddagger}$ for CO dimerization is given by

$$
\Delta G^{\ddagger}(\mathrm{CO}-\mathrm{CO})=1.15+0.0510 \times U(\mathrm{eV})
$$

where $U$ is referenced to the SHE. Note that $\Delta G^{\ddagger}(\mathrm{CO}-\mathrm{CO})$ is independent of $\mathrm{pH}$, since no proton is involved in the reaction.

The minimal onset potential for each step is simply

$$
|U|_{\min }=\max \left(\Delta G^{\ddagger}, \Delta G\right) / e
$$

where $\mathrm{H}^{+}\left(\mathrm{H}_{3} \mathrm{O}^{+} / \mathrm{H}_{2} \mathrm{O}\right)+e^{-}$for each step provides the energy input of $e U$. Here we must compare both $\Delta G^{\ddagger}$ and $\Delta G$ because for some ranges of $U$, the TS can be lower in energy than the final state for some reactions, making the step a simple uphill process.

We use the PBE flavor of DFT theory, as implemented in VASP using cutoffs and core effective potentials (pseudopotentials) as described in the SI.

The $\mathrm{Cu}$ (111) surface serves as a simple but useful model for validating our particular combination of methods since accurate experimental data are available showing a broad range of chemistries $^{20}$ with strong $\mathrm{pH}$ - and potential-dependent selectivity. ${ }^{16}$ The pathways considered are shown in Figure 1:

- starting from adsorbed $\mathrm{CO}$, the (R1) $\mathrm{COH}$ and (R2) $\mathrm{CHO}$ pathways for protonation and the (R3) $\mathrm{CO}-\mathrm{CO}$ path for dimerization constitute all competing options;

- the $\mathrm{COH}$ path (R1) further branches into three channels: advancing along the $C_{1}$ path through either (R1a) the $\mathrm{C}$ path ${ }^{13}$ by removing the $\mathrm{OH}$ group or (R1b) the $\mathrm{CHOH}$ path, and more interestingly, opening up a 
new $\mathrm{C}_{2}$ path by $\mathrm{C}-\mathrm{C}$ coupling through (R1c) the $\mathrm{CO}-$ $\mathrm{COH}$ path;

- the CHO path (R2) converges with the $\mathrm{COH}$ path (R1b) at the point of forming $\mathrm{CHOH}$ while the $\mathrm{CO}-$ $\mathrm{CO}$ path (R3) converges with the $\mathrm{CO}-\mathrm{COH}$ path (R1c) at the point of forming the $\mathrm{COCOH}$ adsorbate.

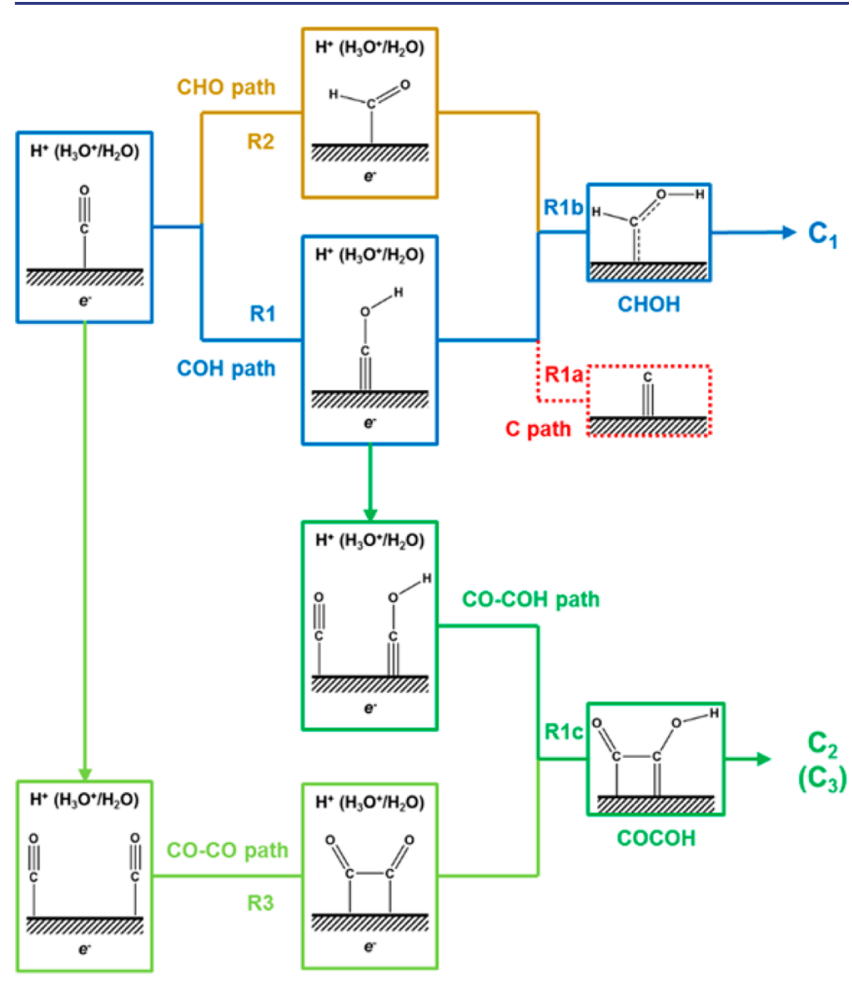

Figure 1. Pathways for the first two steps of COER.

All free energy profiles including the $\mathrm{pH}$ and $U$ dependence are listed in the SI. This is the first proposal of $\mathrm{C}-\mathrm{C}$ coupling through the $\mathrm{CO}-\mathrm{COH}$ path. It leads to a much lower barrier of $0.87 \mathrm{eV}$ at $U=0 \mathrm{~V}$ than the $1.15 \mathrm{eV}$ barrier for the $\mathrm{CO}-\mathrm{CO}$ path, (previously proposed as the path to $\mathrm{C}_{2}$ products). ${ }^{12,15}$ This low barrier arises from the ability of $\mathrm{COH}$ adsorbate to acquire radical character (see discussion in the SI), which remains in the $\mathrm{COCOH}$ adsorbate until it forks to a new $\mathrm{C}_{3}$ path by further coupling with another $\mathrm{CO}$ (discussed in the SI). This might explain why up to $4 \% \mathrm{C}_{3}$ products are observed experimentally, but not beyond $\mathrm{C}_{3} .{ }^{5}$

For $\mathrm{C}_{1}$ pathways, all reactions are modeled at the low coverage limit $\left(\theta_{\mathrm{CO}}=1 / 9\right.$ or $1 / 16$, see Table S1) assuming universal availability of surface hydrogen. Since $\mathrm{C}-\mathrm{C}$ coupling must start with a local coverage of $4 / 9$, we provide a penalty of $0.12 \mathrm{eV}^{21}$ for this $\mathrm{C}_{2}$ pathway to put it on an equal footing with the $\mathrm{C}_{1}$ pathway. This accounts for the energy cost of switching $\mathrm{H}$ with $\mathrm{CO}$ to achieve the high local $\theta_{\mathrm{CO}}$.

To determine the onset potentials, we consider three typical experimental situations, $\mathrm{pH}=1,7$, or 12 .

Case A: At $\mathrm{pH}=1$ (Figure 2), the earliest onset potential of $-0.80 \mathrm{~V}$ starts the $\mathrm{C}_{1}$ path through $\mathrm{COH}$ formation, while the $\mathrm{CHO}$ and $\mathrm{CO}-\mathrm{CO}$ paths lead to barriers higher by 0.08 and $0.43 \mathrm{eV}$, corresponding to kinetic rate ratios at $300 \mathrm{~K}$ of $4 \times$ $10^{-2}: 1$ and $5 \times 10^{-8}: 1$ to the $\mathrm{COH}$ path, respectively. Although their barriers show a positive dependence on $U$, it requires potentials as negative as -1.75 for $\mathrm{CHO}$ and $-3.95 \mathrm{~V}$ for $\mathrm{CO}-$ $\mathrm{CO}$ paths, to have kinetics comparable with the $\mathrm{COH}$ path.

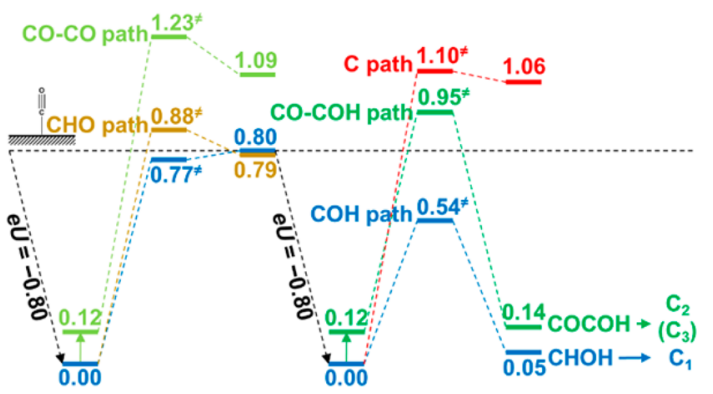

Figure 2. COER free energy profiles at $\mathrm{pH}=1$. The blue line shows the only pathway with significant rates. The predicted onset potential of -0.80 is in excellent agreement with the experimental value of $-0.76 \mathrm{~V}$ (vs SHE) for $\mathrm{CH}_{4}{ }^{16}$

Following $\mathrm{COH}$ formation, the lowest barrier $\mathrm{C}_{1}$ path proceeds through $\mathrm{CHOH}_{\text {ad }}$ (instead of the previously proposed $\mathrm{C}_{\mathrm{ad}}{ }^{13}$ which has a barrier $0.56 \mathrm{eV}$ higher), while the new $\mathrm{C}_{2}$ branch which proceeds by the $\mathrm{CO}-\mathrm{COH}$ path, is suppressed by kinetics (a rate lower by $1 \times 10^{-7}: 1$ at $300 \mathrm{~K}$ compared to the $\mathrm{CHOH}$ path). Thus, both $\mathrm{C}-\mathrm{C}$ coupling mechanisms are blocked kinetically. Consequently there are essentially no $\mathrm{C}_{2}$ products at $\mathrm{pH}=1$. This is consistent with the experimental observation that no $\mathrm{C}_{2} \mathrm{H}_{4}$ is produced on $\mathrm{Cu}(111)$ at $\mathrm{pH}=1 .{ }^{16}$ Our predicted onset potential of $-0.80 \mathrm{~V}$ for $\mathrm{C}_{1}$ products is in excellent agreement with the experimental value of $-0.76 \mathrm{~V}$ (vs SHE) for $\mathrm{CH}_{4}{ }^{16}$

Case B: At $\mathrm{pH}=7$ (Figure 3), the $\mathrm{COH}$ path is again first with a predicted onset potential of $-1.17 \mathrm{~V}$. The $\mathrm{CHO}$ and $\mathrm{CO}-\mathrm{CO}$ pathways are now accessible by kinetic rate ratios at $300 \mathrm{~K}$ of $0.1: 1$ and $0.2: 1$ to the $\mathrm{COH}$ path, respectively. More interestingly, along the dominant $\mathrm{COH}$ path, the branch into $\mathrm{C}_{2}$ products through $\mathrm{CO}-\mathrm{COH}$ coupling is also viable kinetically, with rate ratio at $300 \mathrm{~K}$ of $0.2: 1$ to the $\mathrm{C}_{1}$ channel through the $\mathrm{CHOH}$ path. Consequently the $\mathrm{C}_{1}$ and $\mathrm{C}_{2}$ pathways share the $\mathrm{COH}_{\mathrm{ad}}$ common intermediate. This confirms the experimental conclusion ${ }^{10}$ on $\mathrm{Cu}(111)$ at $\mathrm{pH}=$ 7 that the pathway to $\mathrm{C}_{2} \mathrm{H}_{4}$ has a common intermediate with that to $\mathrm{CH}_{4}$ (based on the same potential dependence, although the common intermediate was incorrectly speculated to be the $\mathrm{CHO}_{\mathrm{ad}}$ ). Our predicted onset potential of $-1.17 \mathrm{~V}$ for the $\mathrm{COH}$ path agrees with the experimental value of $-1.21 \mathrm{~V}$ for both $\mathrm{CH}_{4}$ and $\mathrm{C}_{2} \mathrm{H}_{4}{ }^{10}$ and our predicted rate ratio of 0.2:1 for $\mathrm{C}_{2}: \mathrm{C}_{1}$ along the major $\mathrm{COH}$ path agrees with the experimental $\mathrm{C}_{2} \mathrm{H}_{4}: \mathrm{CH}_{4}$ product ratio of $0.2: 1{ }^{20}$

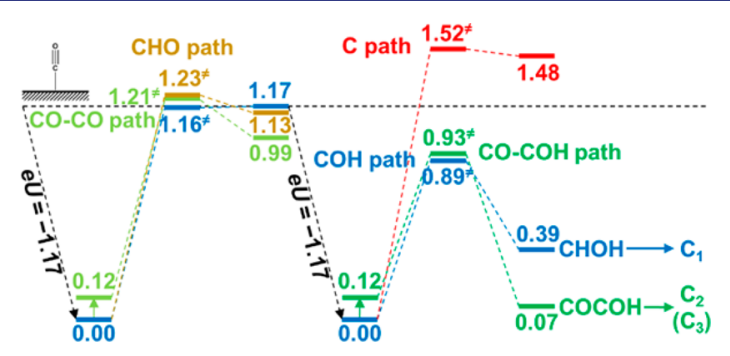

Figure 3. COER free energy profiles at $\mathrm{pH}=7$. The blue line indicates the dominant path, but we predict that the rate for the green line is $20 \%$ of that for the blue line, in agreement with the experimental $\mathrm{C}_{2} \mathrm{H}_{4}: \mathrm{CH}_{4}$ product ratio of $0.2: 1{ }^{20}$ Our predicted onset potential of $-1.17 \mathrm{~V}$ for the $\mathrm{COH}$ path agrees with the experimental value of $-1.21 \mathrm{~V}$ for both $\mathrm{CH}_{4}$ and $\mathrm{C}_{2} \mathrm{H}_{4}{ }^{10}$ 
Case C: At $\mathrm{pH}=12$ (Figure 4), the $\mathrm{CO}-\mathrm{CO}$ path is now initiated at the onset potential of $-1.21 \mathrm{~V}$, which agrees with the experimental value of $-1.26 \mathrm{~V}$ for $\mathrm{C}_{2} \mathrm{H}_{4}$ production at $\mathrm{pH}=$ 12 on $\mathrm{Cu}(111) .{ }^{16}$ Here, both $\mathrm{C}_{1}$ pathways through $\mathrm{COH}_{\mathrm{ad}}$ and $\mathrm{CHO}_{\text {ad }}$ are kinetically inhibited, by rate ratios at $300 \mathrm{~K}$ of $\sim 10^{-5}$ : 1 compared to the $\mathrm{CO}-\mathrm{CO}$ path. Indeed the experiments report very small amounts of $\mathrm{CH}_{4}$ with an onset potential of $-1.46 \mathrm{~V} .^{16}$ This might originate from isolated surface regions where sufficiently high local $\theta_{\mathrm{CO}}$ for $\mathrm{C}-\mathrm{C}$ coupling cannot be reached, due for example, to defects or inhomogeneities in the $\mathrm{CO}$ distribution, in which case $\mathrm{C}_{1}$ pathways might be the only option (if so, our results predict onset potentials for $\mathrm{COH}$ and $\mathrm{CHO}$ paths of -1.48 and -1.51 $\mathrm{V}$, respectively, in agreement with the experimental values). Nevertheless, the experiments suggested that local high $\mathrm{pH}$ might contribute to suppressing formation of $\mathrm{CH}_{4}{ }^{14}{ }^{14} \mathrm{High} \mathrm{pH}$ was used in the case where only $\mathrm{C}_{2}$ and $\mathrm{C}_{3}$ products are produced. ${ }^{22}$ These results are consistent with our suggestion that high $\mathrm{pH}$ boosts selectivity for $\mathrm{C}_{2}$ and $\mathrm{C}_{3}$ products by kinetically blocking $\mathrm{C}_{1}$ pathways. But a major possible complication is the promotion of the hydrogen evolution reaction (HER) by high $\mathrm{pH}$, which reduces the Faraday efficiency of COER.

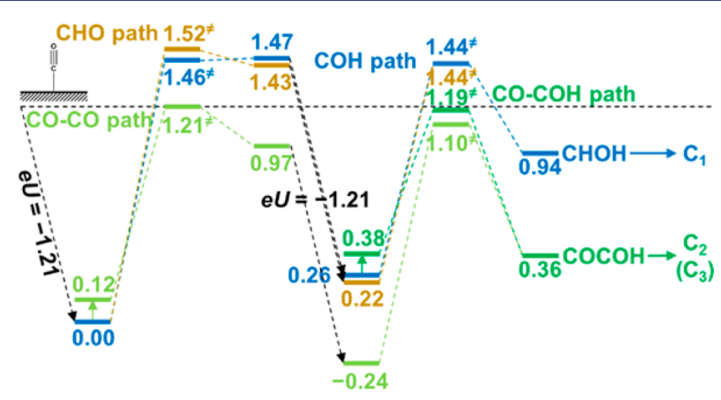

Figure 4. COER free energy profiles at $\mathrm{pH}=12$. The light green line shows the dominant pathway (by a factor of $10^{5}$ at $300 \mathrm{~K}$ ). The predicted onset potential of $-1.21 \mathrm{~V}$ agrees with the experimental value of $-1.26 \mathrm{~V}$ for $\mathrm{C}_{2} \mathrm{H}_{4}$ production at $\mathrm{pH}=12 .{ }^{16}$

Summarizing, we demonstrate a new methodology for accurate prediction of onset potentials from QM calculations while including the $\mathrm{pH}$-dependent mechanisms underlying selectivity for $\mathrm{C}_{1}$ vs $\mathrm{C}_{2}\left(\mathrm{C}_{3}\right)$ products of COER on $\mathrm{Cu}(111)$. At low $\mathrm{pH}=1$, we find that multi-carbon production is suppressed kinetically, so that the $\mathrm{C}_{1}$ pathway proceeds through $\mathrm{COH}_{\mathrm{ad}}$ to $\mathrm{CHOH}_{\mathrm{ad}}$ formation. At neutral $\mathrm{pH}$, we identify a common intermediate $\mathrm{COH}_{\mathrm{ad}}$ for the major mechanism that branches into $\mathrm{C}_{1}$ and $\mathrm{C}_{2}\left(\mathrm{C}_{3}\right)$ production. At high $\mathrm{pH}=12$, we find that selectivity for multi-carbon products arises by kinetically blocking $\mathrm{C}_{1}$ pathways. Of course to selectively produce these $\mathrm{C}$ containing products, we must poison the $\mathrm{HER}$, e.g., structurally engineering $\mathrm{Cu}$ to behave like the oxidederived surface. ${ }^{22}$ We consider that these excellent results with experiment validate the particular combination of methods used here, justifying this as the starting point for examinating other electrochemical reactions.

\section{ASSOCIATED CONTENT}

\section{S Supporting Information}

The Supporting Information is available free of charge on the ACS Publications website at DOI: 10.1021/jacs.5b11390.
Figures S1-S4 and Tables S1-S4, computational details, free energy profiles, radical character of $\mathrm{COH}_{\mathrm{ad}}$ branch to $\mathrm{C}_{3}$ pathway, and coordinates for all structures (PDF)

\section{AUTHOR INFORMATION}

\section{Corresponding Author}

*wag@wag.caltech.edu

Notes

The authors declare no competing financial interest.

\section{ACKNOWLEDGMENTS}

This work was supported by the Joint Center for Artificial Photosynthesis, a DOE Energy Innovation Hub, supported through the Office of Science of the U.S. Department of Energy under Award No. DE-SC0004993. We are grateful to Dr. Robert J. Nielsen, Dr. Manny Soriaga, and Mr. Yufeng Huang for helpful discussions. The computations were carried out on computing resources Zwicky (Caltech) and NERSC.

\section{REFERENCES}

(1) Hori, Y.; Kikuchi, K.; Suzuki, S. Chem. Lett. 1985, 14, 1695.

(2) Hori, Y.; Wakebe, H.; Tsukamoto, T.; Koga, O. Electrochim. Acta 1994, 39, 1833.

(3) Hori, Y. In Modern Aspects of Electrochemistry; Vayenas, C., White, R., Gamboa-Aldeco, M., Eds.; Springer: New York, 2008; Vol. 42, p 89.

(4) Gattrell, M.; Gupta, N.; Co, A. J. Electroanal. Chem. 2006, 594, 1.

(5) Kuhl, K. P.; Cave, E. R.; Abram, D. N.; Jaramillo, T. F. Energy Environ. Sci. 2012, 5, 7050.

(6) Kuhl, K. P.; Hatsukade, T.; Cave, E. R.; Abram, D. N.; Kibsgaard, J.; Jaramillo, T. F. J. Am. Chem. Soc. 2014, 136, 14107.

(7) Hori, Y.; Murata, A.; Takahashi, R.; Suzuki, S. J. Am. Chem. Soc. 1987, 109, 5022.

(8) Hori, Y.; Takahashi, R.; Yoshinami, Y.; Murata, A. J. Phys. Chem. B 1997, 101, 7075 .

(9) Schouten, K. J. P.; Kwon, Y.; van der Ham, C. J. M.; Qin, Z.; Koper, M. T. M. Chem. Sci. 2011, 2, 1902.

(10) Schouten, K. J. P.; Qin, Z.; Gallent, E. P.; Koper, M. T. M. J. Am. Chem. Soc. 2012, 134, 9864.

(11) Peterson, A. A.; Abild-Pedersen, F.; Studt, F.; Rossmeisl, J.; Nørskov, J. K. Energy Environ. Sci. 2010, 3, 1311.

(12) Calle-Vallejo, F.; Koper, M. T. M. Angew. Chem., Int. Ed. 2013, $52,7282$.

(13) Nie, X.; Esopi, M. R.; Janik, M. J.; Asthagiri, A. Angew. Chem., Int. Ed. 2013, 52, 2459.

(14) Roberts, F. S.; Kuhl, K. P.; Nilsson, A. Angew. Chem., Int. Ed. 2015, 54, 5179.

(15) Montoya, J. H.; Shi, C.; Chan, K.; Nørskov, J. K. J. Phys. Chem. Lett. 2015, 6, 2032.

(16) Schouten, K. J. P.; Pérez Gallent, E.; Koper, M. T. M. J. Electroanal. Chem. 2014, 716, 53.

(17) Gunceler, D.; Letchworth-Weaver, K.; Sundararaman, R; Schwarz, K. A.; Arias, T. A. Modell. Simul. Mater. Sci. Eng. 2013, 21, 074005 .

(18) Sundararaman, R.; Goddard, W. A. J. Chem. Phys. 2015, 142, 064107.

(19) Schwarz, K. A.; Sundararaman, R.; Moffat, T. P.; Allison, T. C. Phys. Chem. Chem. Phys. 2015, 17, 20805.

(20) Hori, Y.; Takahashi, I.; Koga, O.; Hoshi, N. J. Mol. Catal. A: Chem. 2003, 199, 39.

(21) Zhang, Y.-J.; Sethuraman, V.; Michalsky, R.; Peterson, A. A. ACS Catal. 2014, 4, 3742.

(22) Li, C. W.; Ciston, J.; Kanan, M. W. Nature 2014, 508, 504. 